\title{
O conhecimento matemático no periódico Evangelisch-Lutherisches Kinderblatt für Südamerika
}

\section{The mathematical knowledge in the journal Evangelisch-Lutherisches Kinderblatt für Südamerika}

\author{
Malcus Cassiano Kuhn ${ }^{1}$ \\ Arno Bayer ${ }^{1}$
}

\begin{abstract}
RESUMO
$\mathrm{O}$ artigo tem por objetivo discutir o conhecimento matemático presente no periódico Evangelisch-Lutherisches Kinderblatt für Südamerika (Jornal para crianças da Igreja Evangélica Luterana da América do Sul), editado pela Igreja Evangélica Luterana do Brasil, na década de 1930. O Sínodo de Missouri, hoje Igreja Evangélica Luterana do Brasil, iniciou missão nas colônias alemãs do Rio Grande do Sul em 1900, fundando congregações religiosas e escolas paroquiais. Baseando-se na história cultural, analisaram-se as 88 edições do periódico Kinderblatt, editado no período de dezembro de 1930 a junho/julho de 1939, em alemão gótico. Foi redigido por pastores luteranos e professores paroquiais e publicado pela Casa Publicadora Concórdia de Porto Alegre. O principal objetivo dos editores do periódico era, de forma lúdica, inserir as crianças na prática religiosa luterana por meio de textos, histórias, informações e curiosidades de cunho moral e religioso e de formação geral. Foi usado, complementarmente, no ensino das diferentes áreas do conhecimento nas escolas paroquiais luteranas gaúchas durante a primeira metade do século XX. Em relação à matemática, constatou-se que os editores valorizavam as habilidades concretas e abstratas do aprendizado matemático através do cálculo escrito e do cálculo mental, em forma de
\end{abstract}

DOI: $10.1590 / 0104-4060.47980$

1 Universidade Luterana do Brasil. Canoas, Rio Grande do Sul, Brasil. Avenida Farroupilha, n 8001, prédio 14, sala 338, Bairro São José. CEP: 92425-900.E-mails: malcusck@yahoo.com.br e bayer@ulbra.br 
atividades lúdicas e prazerosas. Também propunham desafios matemáticos para desenvolver o raciocínio lógico e o pensamento geométrico das crianças.

Palavras-chave: conhecimento matemático; Evangelisch-Lutherisches Kinderblatt für Südamerika; Escolas Paroquiais Luteranas Gaúchas.

\begin{abstract}
The article aims to discuss the mathematical knowledge present in the journal Evangelisch-Lutherisches Kinderblatt für Südamerika (Journal for the children of the Evangelical Lutheran Church of South America), edited by the Lutheran Church in Brazil, in the 1930s. The Missouri Synod, today Evangelical Lutheran Church of Brazil, started its mission in the German colonies of Rio Grande do Sul in 1900, founding religious congregations and parochial schools. Based on cultural history, we analyzed the 88 editions of the Kinderblatt journal, edited in the period of December 1930 to June / July 1939, in Gothic German. It was written by Lutheran pastors and parochial teachers and it was published by Concordia Publishing House of Porto Alegre. The main objective of the journal's editors was, in a playful way; insert the children in the Lutheran religious practice through texts, stories, information and curiosities of moral and religious nature and of general education. It was used, complementarily, in the teaching of the different areas of knowledge in Lutheran parochial schools in Rio Grande do Sul State during the first half of the $20^{\text {th }}$ century. Regarding mathematics, it was found that the editors valued the concrete and abstract skills of the mathematical learning through written calculation and mental calculation, in form of playful and pleasurable activities. They also proposed mathematical challenges to develop logical reasoning and geometric thinking with the children.
\end{abstract}

Keywords: mathematical knowledge; Evangelisch-Lutherisches Kinderblatt für Südamerika; Lutheran Parochial Schools in Rio Grande do Sul.

\title{
1 Introdução
}

Este artigo tem por objetivo discutir o conhecimento matemático presente no periódico Evangelisch-Lutherisches Kinderblatt für Südamerika ${ }^{2}$ (Jornal para crianças da Igreja Evangélica Luterana da América do Sul), publicado na década de

2 Neste artigo também se usará a forma reduzida periódico Kinderblatt para se referir ao periódico Evangelisch-Lutherisches Kinderblatt für Südamerika. 
1930. Trata-se de um estudo iniciado durante a elaboração da tese sobre $O$ ensino da Matemática nas Escolas Evangélicas Luteranas do Rio Grande do Sul durante a primeira metade do século XX e aprofundado durante o estágio Pós-doutoral, junto ao Programa de Pós-Graduação em Ensino de Ciências e Matemática (PPGECIM), da Universidade Luterana do Brasil (ULBRA), no qual se investigou a matemática nas escolas paroquiais luteranas do Rio Grande do Sul-RS.

O movimento migratório no Rio Grande do Sul tem sido objeto de muitas investigações. No âmbito da História da Educação no estado gaúcho, os trabalhos de Kreutz (1991, 1994), Rambo (1994, 1996), Lemke (2001), Arendt (2005) e Weiduschadt $(2007,2012)$ são destaques. Na História da Educação Matemática no RS, destacam-se as pesquisas de Mauro (2005), Kreutz e Arendt (2007), Wanderer (2007) e Kuhn (2015). Enquanto Weiduschadt (2012) faz um estudo geral do periódico Kinderblatt, apontando os temas abordados por ele, neste artigo, investiga-se a matemática presente no periódico, direcionado para as crianças luteranas do RS, na primeira metade do século passado.

O periódico Kinderblatt foi produzido pela Igreja Evangélica Luterana do Brasil (IELB) e publicado pela Casa Publicadora Concórdia ${ }^{3}$, de Porto Alegre. Teve sua $1^{a}$ edição publicada em dezembro de 1930. Com publicações mensais e bimestrais, o periódico foi usado de forma complementar no ensino das diferentes áreas do conhecimento nas escolas paroquiais luteranas gaúchas do século passado, com 88 edições, totalizando 412 páginas. A partir de 1939, devido ao processo de nacionalização do ensino em curso, passou a ser editado em português sob o título $O$ Pequeno Luterano.

Para atingir o propósito desta investigação, a metodologia utilizada assume um caráter qualitativo, embasado em pesquisa documental. Como a temática investigada se insere na História da Educação Matemática no RS, busca-se na história cultural o suporte para discussão. A análise do periódico Kinderblatt está alicerçada em Chartier (1990), no que se refere à produção/circulação (empreendimento dos editores - IELB) e apropriação do impresso (diferentes formas como os leitores se apropriaram da proposta estabelecida pelos editores). Para investigar o periódico se realizaram visitas ao Instituto Histórico da IELB, localizado em Porto Alegre, onde se encontram todas as suas edições. Ao pesquisar minuciosamente cada edição, registraram-se informações gerais sobre elas, apresentadas na seção 4 deste artigo, e se compilaram os excertos relacionados à matemática para posterior estudo e análise, sendo necessária a tradução dos fragmentos escritos em alemão gótico, conforme abordagem realizada na seção 5 .

3 Fundada em 1923, atuava na edição de livros e de periódicos relacionados à literatura religiosa e escolar da IELB. Foi a primeira e a única redatora da IELB, existente até os dias atuais. Antes de sua fundação, os livros e os periódicos eram impressos pela Concordia Publishing House, nos Estados Unidos, e enviados ao Brasil. 
No estudo do periódico Kinderblatt, além do referencial teórico-metodológico, apresenta-se uma breve caracterização das escolas paroquiais luteranas gaúchas do século XX, bem como uma discussão dos conhecimentos matemáticos presentes no periódico.

\section{A história cultural como aporte teórico-metodológico}

Como se investiga um periódico utilizado complementarmente por professores e alunos nas escolas paroquiais da IELB, foca-se no papel do periódico Kinderblatt na dinâmica das aulas de matemática. Segundo Chartier (1990), uma questão desafiadora para a história cultural é o uso que as pessoas fazem dos objetos que lhes são distribuídos ou dos modelos que lhes são impostos, uma vez que há sempre uma prática diferenciada na apropriação dos objetos colocados em circulação. No dizer do autor, é importante compreender as práticas escolares como dispositivos de transformação material de outras práticas culturais e seus produtos. Na perspectiva de Chartier (1990), pode-se dizer que a imprensa pedagógica, aqui representada pelo periódico Kinderblatt, foi um veículo para circulação de ideias que traduzem valores e comportamentos que se deseja ensinar - a ideologia luterana ${ }^{4}$, sendo postas em convergência com outras estratégias políticas e culturais no estado gaúcho.

Chervel (1990) considera importante o estudo histórico da cultura escolar para a compreensão dos elementos que participam da produção/elaboração/ constituição dos saberes escolares e, em particular, da matemática escolar e sua história. Julia (2001) define a cultura escolar como um conjunto de normas que estabelecem conhecimentos a ensinar e condutas a inspirar, e um conjunto de práticas que permitem a transmissão desses conhecimentos e a incorporação desses comportamentos. Isto nos leva a investigar a presença da ideologia luterana nos materiais didáticos editados pela IELB para o ensino da matemática em suas escolas paroquiais gaúchas do século XX.

De acordo com Valente (2007), há uma infinidade de materiais, que junto com os livros didáticos podem permitir compor um quadro da educação matemática de outros tempos. Para o autor, pensar os saberes escolares como elementos da cultura escolar, realizar o estudo histórico da matemática escolar, exige que

4 Conforme Chartier (1990), a ideologia aparece como um projeto de agir sobre a sociedade e está associada a um sistema de valores. A ideologia luterana é representada pela estrita confessionalidade da palavra de Deus e pela disciplina cristã para formação de seres humanos com postura ética e moral exemplar na sociedade. 
se devam considerar os produtos dessa cultura do ensino de matemática, que deixaram traços que permitem o seu estudo, como o periódico Kinderblatt, principal fonte documental desta investigação. Antes, porém, é preciso fazer uma breve abordagem sobre as escolas paroquiais luteranas do século XX no RS.

\section{As escolas paroquiais luteranas gaúchas do século $\mathrm{XX}$}

No Brasil, os princípios cristãos de Lutero se fizeram presentes, a partir de 1824, com a vinda das ideias luteranas através dos primeiros imigrantes alemães. Lutero traçou princípios gerais sobre a educação, os quais se fundamentaram na Bíblia. "A premissa fundamental é de que a Bíblia ensina que Deus criou o universo e mantém, governa e sustenta toda a criação, sendo o homem a obra máxima da criação". (LEMKE, 2001, p. 34).

Nesta perspectiva luterana, o Sínodo Evangélico Luterano Alemão de Missouri ${ }^{5}$, atualmente IELB, começou sua missão nas colônias alemãs do RS, em 1900, fundando congregações religiosas e escolas paroquiais. Para o Sínodo de Missouri era necessário consolidar um campo religioso e fortalecê-lo investindo na escola, influenciando o campo familiar dos seus possíveis fiéis. Os egressos das escolas paroquiais luteranas gaúchas tinham maior conhecimento da Bíblia e uma formação consistente de crenças e valores cristãos tradicionais que enfatizavam a importância do relacionamento com Deus e com outras pessoas. Tinha-se a preocupação pedagógica para que a espiritualidade fosse vivida no dia a dia e não se reduzisse a ritos religiosos.

Numa escola paroquial, o professor, além das matérias seculares, exigidas pelas leis do Estado, antes de tudo, ensinava a religião. O ensino diário de todas as matérias e de toda a educação deveria estar sob a influência da palavra de Deus. Numa escola cristã reinava um espírito cristão, e os alunos não estavam em perigo de aprender coisas que não condiziam com a palavra de Deus e a disciplina cristã. (WARTH, 1979, p. 195).

Portanto, as escolas paroquiais luteranas estavam inseridas num projeto comunitário e missionário que buscava ensinar a língua materna, a matemática,

5 Em 1847, um grupo de imigrantes luteranos alemães da Saxônia fundou, no estado de Missouri (Estados Unidos), o Sínodo Evangélico Luterano Alemão de Missouri, Ohio e Outros Estados, atualmente Igreja Luterana - Sínodo de Missouri. (WARTH, 1979). 
valores culturais, sociais e, principalmente, religiosos. Conforme Lemke (2001, p. 80), "[...] o ensino da palavra de Deus, através da Bíblia, ficava em primeiro lugar, e as demais disciplinas não eram menosprezadas, mas complementavam a educação para servir no mundo". Se a escola formasse o ser humano com postura ética e moral exemplar, este poderia promover transformações sólidas em seu contexto social e seria um verdadeiro colaborador na seara de Deus e para o governo do mundo. As escolas paroquiais luteranas gaúchas foram assim caracterizadas por Weiduschadt (2007):

As escolas eram organizadas de forma multisseriada. As turmas eram compostas de 20 a 40 alunos. Na maioria das vezes, o pastor da comunidade era, ao mesmo tempo, professor. [...] A comunidade sustentava a estrutura física e mantinham o professor da escola. O prédio era muitas vezes o mesmo local do templo. [...] A ligação entre a escola e a igreja era importante, porque logo no início da formação das comunidades o ensino doutrinário e pedagógico era ressaltado e sua suplementação implicava questões econômicas e culturais para a implementação. [...] $\mathrm{O}$ projeto escolar dentro da comunidade religiosa era marcante, a orientação e a obrigação de os pais enviarem os filhos à escola eram quase obrigatórias, com sanções econômicas e morais, caso não concordassem. (WEIDUSCHADT, 2007, p. 166-169).

O Sínodo de Missouri também tinha uma preocupação acentuada em relação aos recursos didáticos usados nas escolas paroquiais, pois este material era escasso e a dificuldade era grande em manter um ensino planificado e organizado. De acordo com Weiduschadt (2007, p. 41), “[...] os livros usados nas escolas paroquiais e utilizados pelos alunos foram produzidos pelas instituições religiosas com objetivo de formar e moldar as condutas e as práticas ao fazer a escolarização das comunidades". Assim, por meio dos livros didáticos e dos periódicos, como o periódico Kinderblatt, que é abordado na seção seguinte, as escolas paroquiais luteranas gaúchas conseguiram desenvolver uma educação integral cristã em todas as disciplinas.

\section{O periódico Evangelisch-Lutherisches Kinderblatt für Südamerika}

O periódico Kinderblatt foi produzido pela IELB para o público infantil, na década de 1930 . Teve sua $1^{\mathrm{a}}$ edição publicada em dezembro de 1930 . A re- 
dação era realizada por professores paroquiais e/ou pastores que se dispunham a redigir, traduzir ou adaptar os textos de forma voluntária, ou seja, não eram remunerados para esta função. Conforme Weiduschadt (2012), os redatores mantinham contato com os leitores, liam as cartas e organizavam o conteúdo do periódico, mas não tinham dedicação exclusiva como redatores. Em geral, acumulavam a função com o exercício do magistério e do pastorado. A edição e a publicação do periódico ficavam por conta da Casa Publicadora Concórdia. As cartas enviadas pelas crianças e por representantes de escolas paroquiais eram encaminhadas para a Casa Publicadora Concórdia, localizada em Porto Alegre, e repassadas aos redatores.

O primeiro redator, considerado fundador do periódico Kinderblatt, foi o pastor Friedrich Theodor Steyer ${ }^{6}$, residente em Sítio, Santa Cruz do Sul, depois em Canoas. Foi redator do periódico no período de dezembro de 1930 até final de 1938. Depois da sua morte, em outubro de 1938, o pastor Karl H. Johannes Fiedler ${ }^{7}$ o substituiu, assumindo a redação em novembro de 1938 até a mudança do periódico para a língua portuguesa, em 1939, devido ao processo de nacionalização do ensino em curso.

A Figura 1 traz um fragmento da $1^{\text {a }}$ edição do periódico Kinderblatt, mostrando informações de sua identificação:

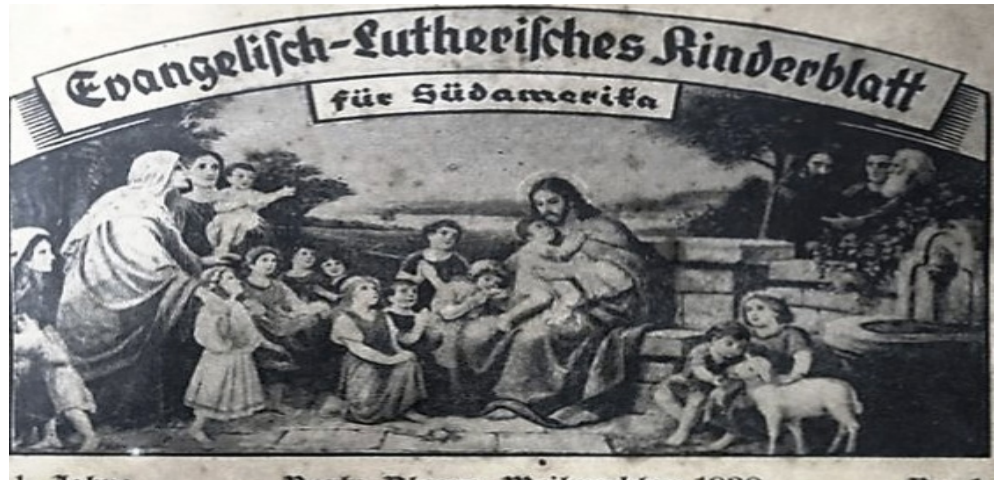

1. Iahyrg. Porto Hlegre, Weilnnadifen 1930

FONTE: Evangelisch-Lutherisches Kinderblatt für Südamerika, dez. 1930, p. 1.

6 O pastor Steyer (1898-1938) nasceu em Dresden, Alemanha, formou-se no Seminário Concórdia, em Porto Alegre, em 1925, e atuou como estatístico e secretário da IELB.

7 O pastor Fiedler formou-se em 1929, na Alemanha, veio ao Brasil no ano de 1932, trabalhou e atuou como professor paroquial em Bom Jesus, São Lourenço do Sul, e professor do Seminário Concórdia. 
Além do título do periódico, Evangelisch-Lutherisches Kinderblatt für Südamerika, aparece escrito: ano 1, Porto Alegre, Natal de 1930, número 1. Também se observa a imagem de Jesus acolhendo as crianças, que tem uma relação direta com um dos princípios luteranos de que a salvação de todos os homens se dá pela fé em Jesus Cristo. (LEMKE, 2001). Ressalta-se que esta apresentação inicial do periódico, inclusive a imagem, foi mantida em todas as suas edições, as quais foram editadas com base em princípios morais e educacionais idealizados pela IELB. O Quadro 1 reúne informações gerais sobre as edições do periódico Kinderblatt:

QUADRO 1 - AS EDIÇÕES DO PERIÓDICO KINDERBLATT

\begin{tabular}{|c|c|c|}
\hline Ano & Edições & Total de páginas \\
\hline $1-1930 / 1931$ & 12 mensais & 48 \\
\hline $2-1932$ & 12 mensais & 48 \\
\hline $3-1933$ & 4 mensais e 4 bimestrais & 48 \\
\hline $4-1934$ & 8 mensais e 2 bimestrais & 48 \\
\hline $5-1935$ & 10 mensais e 1 bimestral & 48 \\
\hline $6-1936$ & 8 mensais e 2 bimestrais & 48 \\
\hline $7-1937$ & 8 mensais e 2 bimestrais & 48 \\
\hline $8-1938$ & 8 mensais e 2 bimestrais & 48 \\
\hline $9-1939$ & 3 mensais e 2 bimestrais & 28 \\
\hline Total & 73 mensais e 15 bimestrais & 412 \\
\hline
\end{tabular}

FONTE: Evangelisch-Lutherisches Kinderblatt für Südamerika, 1930-1939.

Observa-se, no Quadro 1, que o periódico Kinderblatt foi editado 12 vezes nos dois primeiros anos de edição (1930/1931 e 1932) e nos anos seguintes houve também algumas edições bimestrais, especialmente nos meses de janeiro e fevereiro. Foram 88 edições em seus quase 9 anos de circulação, sendo 73 mensais e 15 edições bimestrais. As edições mensais continham 4 páginas e as edições bimestrais 8 páginas, totalizando 48 páginas anuais e 412 páginas em toda sua história. A última edição do periódico foi publicada em junho/julho de 1939. A partir de agosto/setembro de 1939, o periódico Kinderblatt foi substituído pelo periódico $O$ Pequeno Luterano, editado em língua portuguesa.

O periódico Kinderblatt tinha como principal objetivo inserir as crianças na prática religiosa luterana por meio de textos, histórias, informações e curiosidades de cunho moral e religioso e de formação geral. Os editores usaram a estratégia de elaborar um periódico lúdico, com linguagem e imagens voltadas ao público infantil. Nas edições do periódico havia um chamamento para pais 
e professores paroquiais incentivarem as crianças para a sua leitura. A estratégia dos editores de receber cartas dos seus leitores, especialmente de alunos das escolas paroquiais luteranas gaúchas, com depoimentos e respostas das charadas e desafios propostos no periódico, além dos relatos dos professores com informações sobre as escolas paroquiais e o número de alunos, contribuiu para circulação e inserção do periódico Kinderblatt entre o público infantil. Isto foi reforçado pelo uso do periódico pelos professores paroquiais, de forma complementar, no ensino de diferentes conteúdos. Na sequência desse estudo, abordam-se conhecimentos matemáticos presentes no periódico Kinderblatt.

\section{A matemática no periódico Evangelisch-Lutherisches Kinderblatt für Südamerika}

Embora fosse um livro não formal, mas similar ao catecismo, o periódico Kinderblatt era usado pelos professores e alunos nas escolas paroquiais luteranas gaúchas para conteúdos nas diferentes áreas do conhecimento. Com relação aos conhecimentos matemáticos, presentes nesse periódico, observou-se que os editores apostaram numa estratégia envolvendo uma matemática mais lúdica, diferente das propostas de ensino apresentadas nas aritméticas da série Ordem e Progresso e da série Concórdia, editadas pela IELB para suas escolas paroquiais, na primeira metade do século XX.

Neste artigo, apresentam-se os principais fragmentos relacionados com matemática e localizados no periódico Kinderblatt. Na edição de novembro de 1933, encontrou-se o primeiro excerto, conforme ilustra a Figura 2.

A Figura 2 traz um excerto do periódico Kinderblatt que apresenta uma forma prática de calcular a tabuada de 11 a 19, por meio de dois exemplos (16 x 18 e 13 x 19). Estes cálculos eram desenvolvidos nas escolas paroquiais, pois, de acordo com Sommer (1984, p. 70), “[...] o estudo da aritmética se dava com ênfase nos cálculos mentais, onde além da tabuada até 10, exigia-se o cálculo rápido da tabuada de 11 a 19 ". 


\section{FIGURA 2 - FAZENDO A GRANDE TABUADA RAPIDA- MENTE $^{8}$}

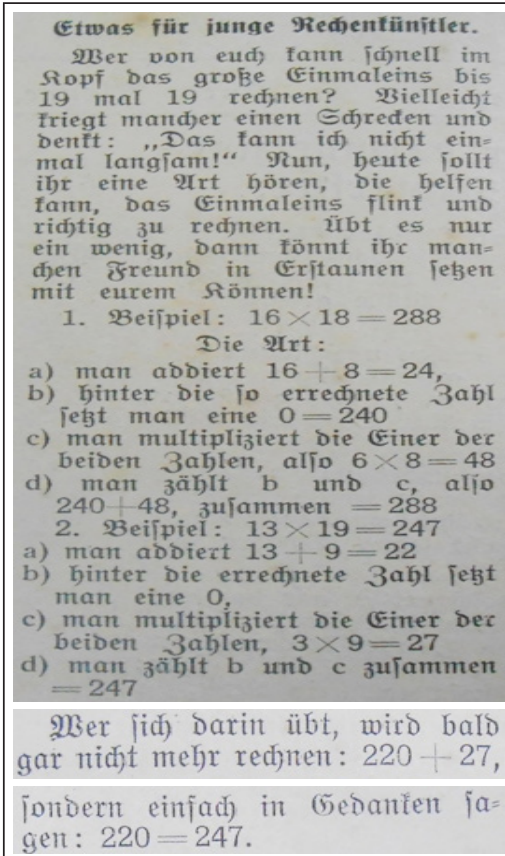

Tradução: Algo para jovens artistas do cálculo.

Algum de vocês pode rapidamente fazer de cabeça, a grande tabuada até 19 x 19? Talvez algum pode ficar assustado, pensando: "Eu não posso, sou lento!" Bem, hoje você vai ver uma maneira que pode ajudar a calcular a multiplicação de modo ágil e preciso. Treine só um pouco, em seguida, você pode surpreender algum amigo com suas habilidades!

1. Exemplo: $16 \times 18=288$

A maneira:

a) adição de $16+8=24$,

b) acrescenta-se um 0 ao lado do último algarismo do número obtido $=240$

c) multiplicam-se os algarismos das unidades dos dois números, então 6 × $8=48$

d) somam-se os resultados de b e c, que são $240+48=288$

2. Exemplo: $13 \times 19=247$

a) adição de $13+9=22$

b) acrescenta-se um 0 ao lado do último algarismo do número obtido $=220$

c) multiplicam-se os algarismos das unidades dos dois números, então 3 x $9=27$

d) somam-se os resultados de b e c, que são $220+27=247$

Quem se treinar, em breve deixará de contar: $220+27$, apenas fará mentalmente $220=247$

FONTE: Evangelisch-Lutherisches Kinderblatt für Südamerika, nov. 1933, p. 42-43.

Em outra edição do periódico Kinderblatt encontrou-se uma multiplicação curiosa envolvendo o número 37 e os múltiplos de 3 compreendidos entre 3 e 27, coforme apresentado na Figura 3:

8 A tabuada de 1 a 10 era conhecida por pequena tabuada e a tabuada de 11 a 20 era denominada grande tabuada. 


\begin{tabular}{|c|c|}
\hline 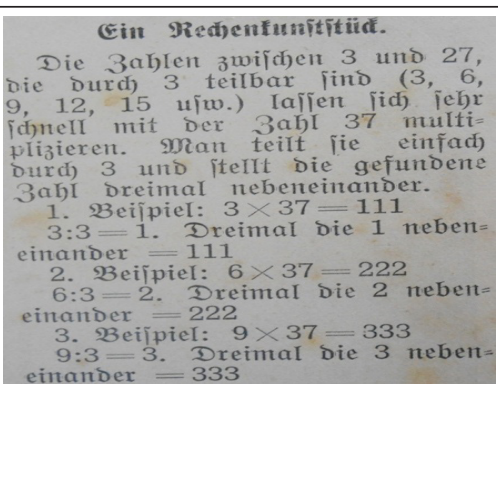 & $\begin{array}{l}\text { Tradução: Uma façanha de cálculo. } \\
\text { Os números entre } 3 \text { e } 27 \text {, divisíveis } \\
\text { por } 3 \text { são } 3,6,9,12,15 \text {, etc. e podem ser } \\
\text { multiplicados muito rapidamente pelo } \\
\text { número } 37 \text {. Dividi-se eles por } 3 \text { e se coloca } \\
\text { o número obtido três vezes ao lado do outro. } \\
1 . \text { Exemplo: } 3 \text { x } 37=111 \\
3 \div 3=1 \text {. Três vezes o } 1 \text { lado a lado }=111 \\
2 . \text { Exemplo: } 6 \text { x } 37=222 \\
6 \div 3=2 \text {. Três vezes o } 2 \text { lado a lado }=222 \\
3 . \text { Exemplo: } 9 \text { x } 37=333 \\
9 \div 3=3 \text {. Três vezes o } 3 \text { lado a lado }= \\
333\end{array}$ \\
\hline
\end{tabular}

FONTE: Evangelisch-Lutherisches Kinderblatt für Südamerika, mar./abr. 1934, p. 16.

Observa-se que o fragmento, mostrado na Figura 3, apresenta a curiosidade somente para os três primeiros casos $(3 \times 37,6 \times 37$ e 9 × 37). Já na edição de setembro de 1951 do periódico O Pequeno Luterano, encontrou-se a curiosidade com o número 37 , de forma semelhante e escrita em português, porém, demonstrada para os nove casos possíveis, conforme se pode observar na Figura 4. Ressalta-se que o excerto, localizado no periódico Kinderblatt, explica e mostra como se obtém o algarismo que se repete no produto através de uma divisão, enquanto o fragmento, encontrado no periódico O Pequeno Luterano, fala que a soma dos algarismos iguais de cada produto é igual ao multiplicador a partir do qual ele originou-se.

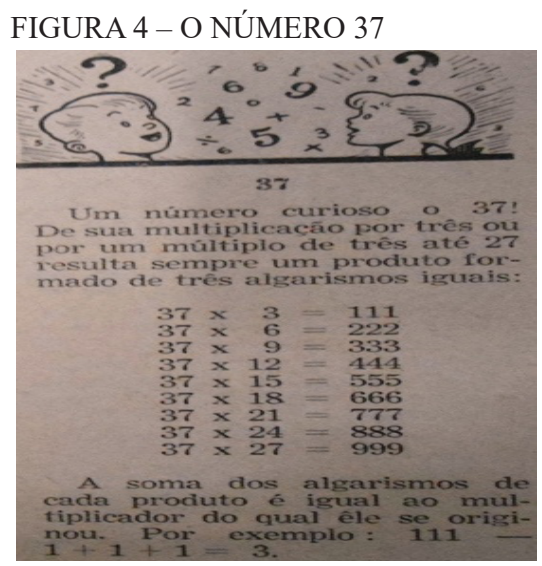

FONTE: O Pequeno Luterano, set. 1951, p. 44. 
Destaca-se que o procedimento para calcular a tabuada de 11 a 19 , apresentado na Figura 2, e a curiosidade envolvendo multiplicações com o número 37, mostrada nas Figuras 3 e 4, evidenciam a preocupação dos editores em desenvolver habilidades para o cálculo mental e para o cálculo escrito com as crianças que frequentavam as escolas paroquiais luteranas gaúchas do século passado.

A Figura 5 traz um desafio matemático encontrado no periódico Kinderblatt, edição de junho de 1934:

\section{FIGURA 5 - O DESAFIO DO CARA- COL}

\begin{tabular}{|c|c|}
\hline Redenaufgabe. & Tradução: Tarefa de cálculo. \\
\hline 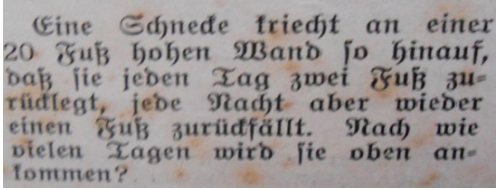 & $\begin{array}{l}\text { Um caracol sobe uma parede com } 20 \text { pés } \\
\text { de altura. Durante o dia, sobe } 2 \text { pés, mas } \\
\text { todas as noites, escorrega } 1 \text { pé. Depois de } \\
\text { quantos dias ele vai chegar ao topo? }\end{array}$ \\
\hline
\end{tabular}

FONTE: Evangelisch-Lutherisches Kinderblatt für Südamerika, jun. 1934, p. 19.

O periódico traz o desafio matemático apresentado na Figura 5, sendo que não foi localizada a sua resposta nas edições posteriores do periódico Kinderblatt. Todavia, o caracol levará 19 dias para subir a parede com 20 pés de altura. Desafios semelhantes a este são encontrados em livros de matemática atuais e em publicações sobre curiosidades e desafios matemáticos.

No periódico Kinderblatt, também, localizou-se um desafio envolvendo formas geométricas, conforme excerto apresentado na Figura 6:

\section{FIGURA 6 - A CRUZ PARTIDA}

\begin{tabular}{|c|c|}
\hline 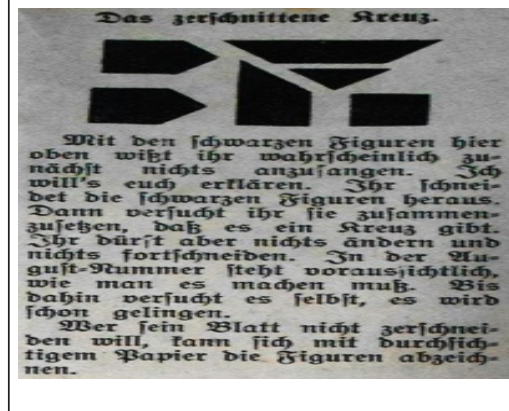 & $\begin{array}{l}\text { Tradução: A cruz partida. } \\
\text { Talvez você não sabe o que fazer } \\
\text { inicialmente com estas peças pretas. Então, } \\
\text { vou explicar o que deve fazer. Você recorta } \\
\text { as peças pretas. Depois você tenta juntá- } \\
\text { las para formar uma cruz. Mas, você não } \\
\text { deve modificar ou cortar qualquer coisa. Na } \\
\text { edição de agosto se mostrará a solução. Até } \\
\text { então, você deve tentar fazê-lo com sucesso. } \\
\text { Quem não quer recortar a revista, pode } \\
\text { conseguir as figuras com papel transparente. }\end{array}$ \\
\hline
\end{tabular}

FONTE: Evangelisch-Lutherisches Kinderblatt für Südamerika, jun. 1934, p. 23. 
A Figura 6 mostra um desafio com seis formas geométricas que devem ser juntadas para formar uma cruz. A solução deste desafio foi encontrada na edição de agosto de 1934 do periódico, conforme mostrado na Figura 7:

FIGURA 7 - SOLUÇÃO DA CRUZ PARTIDA

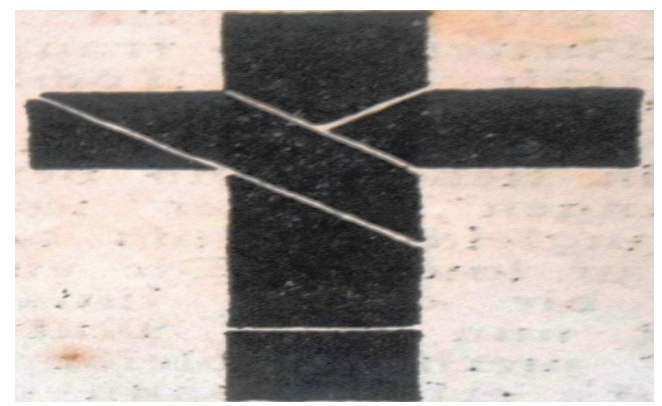

FONTE: Evangelisch-Lutherisches Kinderblatt für Südamerika,ago. 1934, p. 31.

Os editores do periódico Kinderblatt esperavam e recebiam cartas dos seus leitores infantis com as possíveis soluções das charadas e dos desafios propostos no periódico. Registra-se a falta de informações sobre a quantidade de cartas enviadas pelos leitores, cuja referência de agradecimento e incentivo para envio, geralmente, eram feitos no final de cada edição. As cartas eram postadas individualmente ou por grupos de alunos de escolas paroquiais luteranas, com incentivo do professor paroquial, o que indica a utilização do periódico em sala de aula. Esta estratégia dos editores ajudava a despertar o interesse das crianças para aquisição e leitura do periódico.

Na Figura 8, apresenta-se mais uma curiosidade matemática relacionada com a operação de multiplicação, localizada no periódico Kinderblatt.

Observa-se que o excerto, mostrado na Figura 8, assim como os fragmentos, observados nas Figuras 2, 3 e 4, são curiosidades focadas na operação de multiplicação. De acordo com estudos realizados por Kuhn (2015), esta constância está relacionada com dificuldades de aprendizagem dos alunos das escolas paroquiais luteranas gaúchas do século passado, nesta operação matemática. Além disto, havia uma preocupação em instrumentalizar os alunos para o cálculo de forma prática e rápida, refletindo-se ainda uma tradição pedagógica de memorização. (VALENTE; PINHEIRO, 2015). 
FIGURA 8 - MULTIPLICAÇÃO DE NÚMEROS COM ALGARISMOS DAS DEZENAS IGUAIS

\begin{tabular}{|c|c|}
\hline 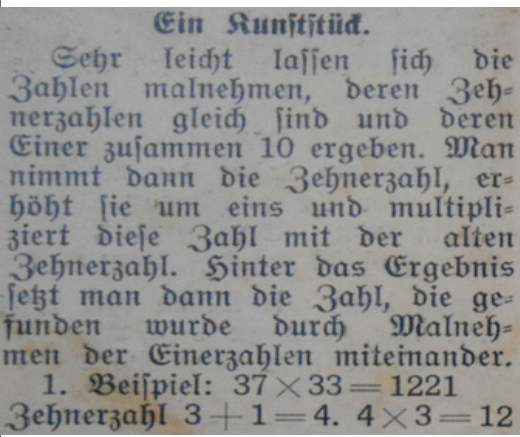 & 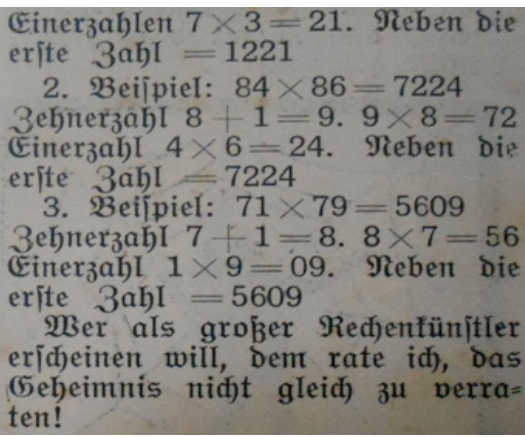 \\
\hline $\begin{array}{l}\text { Soma-se } 1 \text { a este algarismo, obser } \\
\text { multiplica a soma obtida pelo alg } \\
\text { multiplica-se os algarismos das uni } \\
\text { resultados obtidos nas multiplicaçõe } \\
\text { Exemplo 1: } 37 \text { x } 33=1221 \\
\text { Algarismo da dezena: } 3+1=4 \\
\text { Algarismos das unidades: } 7 \text { x } 3= \\
\text { Exemplo 2: } 84 \text { x } 86=7224 \\
\text { Algarismo da dezena: } 8+1=9 \\
\text { Algarismos das unidades: } 4 \text { x } 6= \\
\text { Exemplo } 3: 71 \text { x } 79=5609 \\
\text { Algarismo da dezena: } 7+1=8 \text {, } \\
\text { Algarismos das unidades: } 1 \text { x } 9= \\
\text { Quem quizer ser considerado un }\end{array}$ & $\begin{array}{l}=72 \\
\text { untando-se os números }=7224 \\
=56 \\
\text { untando-se os números }=5609 \\
\text { de gênio matemático, eu aconsell }\end{array}$ \\
\hline
\end{tabular}

FONTE: Evangelisch-Lutherisches Kinderblatt für Südamerika, jul. 1934, p. 28.

Na Figura 9 são apresentadas brincadeiras com palitos de fósforo, encontradas no periódico Kinderblatt: 
FIGURA 9 - BRINCADEIRAS COM PALITOS DE FÓSFORO

\begin{tabular}{|c|c|}
\hline 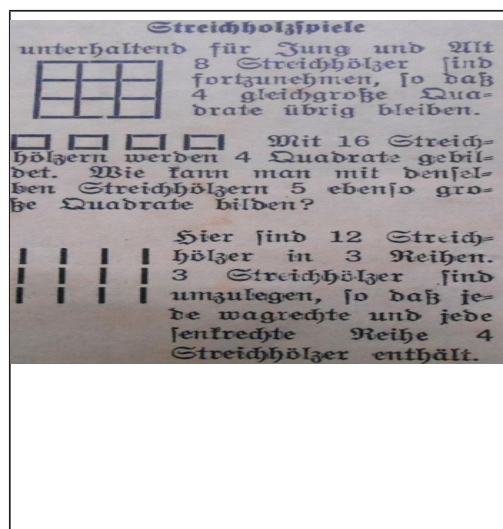 & $\begin{array}{l}\text { Tradução: Brincadeiras com palitos de } \\
\text { fósforo. } \\
\text { Entretenimento para crianças e adultos: } \\
8 \text { palitos de fósforo são retirados, de } \\
\text { modo que permaneçam quatro quadrados } \\
\text { iguais. } \\
\text { Com } 16 \text { palitos de fósforo são formados } \\
4 \text { quadrados. Como se pode formar } 5 \\
\text { quadrados iguais com esses mesmos palitos } \\
\text { de fósforo? } \\
\text { Aqui estão } 12 \text { palitos de fósforo em } 3 \\
\text { linhas. } 3 \text { palitos de fósforo são deslocados, } \\
\text { de modo que cada linha horizontal e vertical } \\
\text { contenha } 4 \text { palitos de fósforo. }\end{array}$ \\
\hline
\end{tabular}

FONTE: Evangelisch-Lutherisches Kinderblatt für Südamerika, out. 1937, p. 40.

As curiosidades e desafios com palitos de fósforo, mostrados na Figura 9, envolvem a construção de formas geométricas, explorando a criatividade das crianças e o seu raciocínio lógico. Atividades semelhantes ainda são encontradas em publicações atuais sobre curiosidades e desafios matemáticos.

A Figura 10 apresenta uma curiosidade matemática envolvendo os números naturais de 1 a 31 , encontrada neste periódico.

O excerto, mostrado na Figura 10, é uma curiosidade matemática que explora a adivinhação de números entre 1 e 31 e exige a interação e a atenção entre os envolvidos, explorando o pensamento matemático de forma lúdica. A localização de cada número nas colunas está associada a sua representação no sistema de numeração de base 2. Por exemplo:

a) $11_{10}=1101_{2}$, pois $11=1 \times 2^{0}+1 \times 2^{1}+0 \times 2^{2}+1 \times 2^{3}$. Logo, o número 11 se encontra na $1^{\mathrm{a}}, 2^{\mathrm{a}}$ e $4^{\mathrm{a}}$ colunas da tabela apresentada na Figura 10;

b) $31_{10}=11111_{2}$, pois $31=1 \times 2^{0}+1 \times 2^{1}+1 \times 2^{2}+1 \times 2^{3}+1 \times 2^{4}$. Portanto, o número 31 se encontra em todas as cinco colunas da tabela. 
FIGURA 10 - ADIVINHANDO NÚMEROS

\begin{tabular}{rrrrr}
\multicolumn{3}{c}{ 3aIfer } & \multicolumn{3}{c}{ caters } \\
1 & 2 & 4 & 8 & 16 \\
3 & 3 & 5 & 9 & 17 \\
5 & 6 & 6 & 10 & 18 \\
7 & 7 & 7 & 11 & 19 \\
9 & 10 & 12 & 12 & 20 \\
11 & 11 & 13 & 13 & 21 \\
13 & 14 & 14 & 14 & 22 \\
15 & 15 & 15 & 15 & 23 \\
17 & 18 & 20 & 24 & 24 \\
19 & 19 & 21 & 25 & 25 \\
21 & 22 & 22 & 26 & 26 \\
23 & 23 & 23 & 27 & 27 \\
25 & 26 & 28 & 28 & 28 \\
27 & 27 & 29 & 29 & 29 \\
29 & 30 & 30 & 30 & 30 \\
31 & 31 & 31 & 31 & 31
\end{tabular}

Gdreibe diefe Tabelle auf einen Bettel oder ein Stiud weike ßappe. Irum bitte iemanden, fich eine be= liebige 3 abl bis höditens 31 3u Denfen. Fib ibm dann Die Iabelle

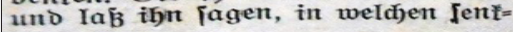

ređten Reiben die gedadyte 3abI iid befindet. Ein Blid auf bieje Reiben und Du balt bie 3abl er= raten!

Nefinen wir an, ex দабе jid 25 gebaht. Dann müs er bir Jagen, Dak Die 25 in Der exiten, pierten

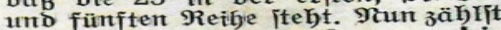
Du rajd die 3ablen zujammen, bie in Der exiten waagereaten Reibe bei Den betreffenden penfred)ten Reifen ji finden. In diejein Jalle aljo 1 und 8 und 16. Die Summe ijt tatiäd)ia 25. Soat jia jeinand 18 gedadt, io imis er die sweite und finfte Reibje nenten. Du zäblịt Dant 2 und 16 miammen und hait Die riatige \&öpung. Soat ex fia) 1 gebad)t, io fam ex mux bie exite Reibe melden und Du findeit jo ohre weiteres die 1 ; Gat er bage= gett îđ 31 gedad)t, io wird ex [ $\alpha=$ gen, fie itumbe in allen Reiben. Dam ergibt fid aus 1 und 2 und 4 und 8 und 16 fanell bie 31 .

\section{Tradução: Adivinhando números.}

Escreva esta tabela em um pedaço de papel ou em um pedaço de papelão branco. Então, peça para alguém pensar em um número até 31 . Em seguida, mostre a tabela e deixe-o dizer em quais colunas o número pensado está localizado. Um olhar sobre essas colunas e você adivinhará o número!

Suponha que ele tenha pensado 25. Então, ele deverá dizer-lhe que o 25 está na primeira, quarta e quinta colunas. Então, você soma rapidamente os números da primeira linha que estão nas colunas indicadas, ou seja, 1 e 8 e 16 . A soma é realmente 25. Alguém pensou 18, devendo informar a segunda e quinta colunas. Somando 2 e 16 , temos a resposta certa. Se o número pensado está apenas na primeira coluna, você vai encontrar tão facilmente 1 como resposta. Se alguém pensar 31, vai dizer que o número está em todas as colunas. Somando-se 1, 2, 4, 8 e 16, rapidamente se chegará em 31.

FONTE: Evangelisch-Lutherisches Kinderblatt für Südamerika, jan./fev. 1939, p. 7.

Para finalizar esta investigação, apresentam-se suas considerações finais na sequência.

\section{Considerações finais}

Através da Casa Publicadora Concórdia, a IELB editou e publicou livros didáticos e periódicos, como o periódico Evangelisch-Lutherisches Kinderblatt für Südamerika, de acordo com seus princípios morais e educacionais. Além de 
educarem e doutrinarem pela palavra de Deus, os periódicos editados pela Igreja Luterana se direcionavam para o ensino das crianças nas escolas paroquiais, trazendo artigos com orientações didáticas e informações sobre conteúdos formais.

O periódico Kinderblatt teve 88 edições (mensais/bimestrais), no período de dezembro de 1930 a junho/julho de 1939, quando foi substituído pelo periódico $O$ Pequeno Luterano, devido ao processo de nacionalização do ensino. O principal objetivo dos editores do periódico era, de forma lúdica, inserir as crianças na prática religiosa luterana por meio de textos, histórias, informações e curiosidades de cunho moral e religioso e de formação geral. Dessa forma, foi usado pelos professores paroquiais, complementarmente, no ensino das diferentes áreas do conhecimento nas escolas paroquiais luteranas gaúchas durante a primeira metade do século XX.

Fundamentando-se no referencial teórico-metodológico da história cultural, investigou-se o conhecimento matemático presente no periódico Kinderblatt, editado para o público infantil, pela IELB. Identificou-se a abordagem de conhecimentos relacionados à operação de multiplicação com números naturais, divisibilidade, formas geométricas e sistemas de numeração em base 10 e base 2. Nas aulas de matemática das escolas paroquiais luteranas gaúchas do século passado, priorizava-se o ensino dos números naturais, sistemas de medidas, frações e números decimais, complementando-se com a matemática comercial e financeira e a geometria. Esse ensino deveria acontecer de forma prática e articulada com as necessidades dos futuros agricultores, observando-se sempre a ideologia luterana. Nesse sentido, os editores do periódico valorizavam as habilidades concretas e abstratas do aprendizado matemático através do cálculo escrito e, principalmente, do cálculo mental, em forma de atividades lúdicas e prazerosas. Aponta-se que o fazer de cabeça reflete a tradição pedagógica da memorização, presente nas escolas paroquiais luteranas do século $\mathrm{XX}$. Acrescenta-se que os editores, também, propunham desafios matemáticos para desenvolver o raciocínio lógico e o pensamento geométrico das crianças. Curiosidades e desafios matemáticos, semelhantes aos localizados no periódico Kinderblatt, estão presentes nos livros de matemática atuais e em publicações, como as de Malba Tahan.

Com uma estratégia de abordagem da matemática de maneira utilitária e formativa, os editores do periódico Kinderblatt esperavam que as crianças se apropriassem dos conhecimentos matemáticos, e no futuro, realizassem a administração correta do seu orçamento familiar e o gerenciamento da sua propriedade rural.

Por meio deste estudo histórico sobre o conhecimento matemático no periódico Evangelisch-Lutherisches Kinderblatt für Südamerika, pretende-se contribuir para a História da Educação Matemática. Esta pesquisa ainda tem sua 
KUHN, M. C.; BAYER, A. O conhecimento matemático no periódico Evangelisch-Lutherisches...

continuidade através da investigação da matemática no periódico $O$ Pequeno Luterano, editado de agosto de 1939 a junho de 1966.

\section{REFERÊNCIAS}

ARENDT, I. C. Representações de Germanidade, Escola e Professor no Allgemeine Lehrerzeitung Für Rio Grande do Sul [Jornal Geral para o Professor no Rio Grande do Sul]. Tese (Doutorado em História) - Universidade do Vale do Rio dos Sinos, São Leopoldo, 2005.

CHARTIER, R. A História Cultural: entre práticas e representações. Lisboa: Difel, 1990. CHERVEL, A. História das disciplinas escolares - reflexões sobre um campo de pesquisa. Teoria \& Educação, Porto Alegre, n. 2, p. 177-229, 1990.

EVANGELISCH-LUTHERISCHES Kinderblatt Für Südamerika. Porto Alegre: Casa Publicadora Concórdia, 1930-1939.

JULIA, D. A cultura escolar como objeto histórico. Revista Brasileira de História da Educação, Campinas, n. 1, p. 9-43, jan./jun. 2001.

KREUTZ, L. O professor paroquial: magistério e imigração alemã. Porto Alegre: Ed. da UFRGS; Caxias do Sul: EDUCS, 1991.

KREUTZ, L. Material didático e currículo na escola teuto-brasileira. São Leopoldo: Ed. UNISINOS, 1994.

KREUTZ, L.; ARENDT, I. C. (Org.). Livros escolares das escolas de imigração alemã no Brasil (1832-1940). Acervo documental e de pesquisa. Biblioteca UNISINOS. São Leopoldo, 2007. 3 CD-ROM.

KUHN, M. C. O ensino da matemática nas escolas evangélicas luteranas do Rio Grande do Sul durante a primeira metade do século XX. Tese (Doutorado em Ensino de Ciências e Matemática) - Universidade Luterana do Brasil, Canoas, 2015.

LEMKE, M. D. Os princípios da educação cristã luterana e a gestão de escolas confessionárias no contexto das ideias pedagógicas no sul do Brasil (1824-1997). Canoas: Ed. ULBRA, 2001.

MAURO, S. Uma história da matemática escolar desenvolvida por comunidades de origem alemã no Rio Grande do Sul no final do século XIX e início do século XX. Tese (Doutorado em Educação Matemática) - Universidade Estadual Paulista, Rio Claro, 2005.

RAMBO, A. B. A escola comunitária teuto-brasileira católica. São Leopoldo: Ed. UNISINOS, 1994. 
RAMBO, A. B. A escola comunitária teuto-brasileira católica: a associação de professores e a escola normal. São Leopoldo: Ed. UNISINOS, 1996.

SOMMER, A. Reminiscências da Colônia Teutônia: Estrela décadas 20 e 30. São Leopoldo: Rotermund, 1984.

VALENTE, W. R. História da Educação Matemática: interrogações metodológicas. REVEMAT - Revista Eletrônica de Educação Matemática, UFSC, v. 2.2, p. 28-49, 2007.

VALENTE, W. R.; PINHEIRO, N. V. L. Chega de decorar a tabuada! - As cartas de Parker e a árvore do cálculo na ruptura de uma tradição. Educação Matemática em Revista - RS, Canoas, v. 1, n. 16, p. 22-37, 2015.

WANDERER, F. Escola e Matemática Escolar: mecanismos de regulação sobre sujeitos escolares de uma localidade rural de colonização alemã no Rio Grande do Sul. Tese (Doutorado em Educação) - Universidade do Vale do Rio dos Sinos, São Leopoldo, 2007.

WARTH, C. H. Crônicas da Igreja: fatos históricos da Igreja Evangélica Luterana do Brasil (1900 a 1974). Porto Alegre: Concórdia, 1979.

WEIDUSCHADT, P. O Sínodo de Missouri e a educação pomerana em Pelotas e São Lourenço do Sul nas primeiras décadas do século XX: identidade e cultura escolar. Dissertação (Mestrado em Educação) - Universidade Federal de Pelotas, Pelotas, 2007.

WEIDUSCHADT, P. A revista "O Pequeno Luterano" e a formação educativa religiosa luterana no contexto pomerano em Pelotas - RS (1931-1966). Tese (Doutorado em Educação) - Universidade do Vale do Rio dos Sinos, São Leopoldo, 2012.

Texto recebido em 15 de agosto de 2016. Texto aprovado em 14 de dezembro de 2016. 
